\title{
The Effectiveness of Chitosan and Snail Seromucous as Anti Tuberculosis Drugs
}

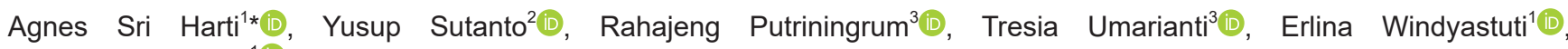 \\ Mellia Silvy Irdianty $^{1}$
}

${ }^{1}$ Departement of Nursing, Kusuma Husada University Surakarta, Surakarta, Indonesia; ${ }^{2}$ Pulmonary Disease Study Program, Faculty of Medicine, Sebelas Maret University, Surakarta, Indonesia; ${ }^{3}$ Midwife Professional Study Program, Faculty of Health Sciences, Kusuma Husada University Surakarta, Surakarta, Indonesia

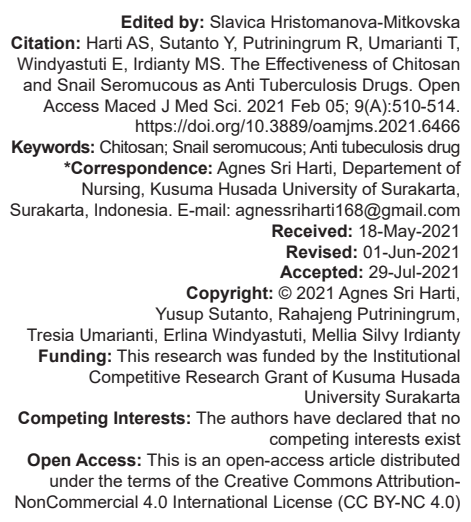

\begin{abstract}
BACKGROUND: Tuberculosis (TB) disease is an infection caused by Mycobacterium tuberculosis (MTB) and is transmitted through sputum droplets of sufferers or suspect TB in the air. Chitosan has been widely used in the biomedical and pharmaceutical fields because it is a biocompatible, biodegradable, non-toxic, antimicrobial, and hydrating agent with positive effects on wound healing. Seromucous of snail has anti-tumor bioactivity and is nontoxic to lymphocyte cells, and can even stimulate lymphocyte proliferation. Seromucous of snail as glycoprotein containing carbohydrates; $\alpha-1$ globulin-oromucoid fraction; glycans, peptides, glycopeptides, and chondroitin sulfate.

AIM: This study was to determine the effectiveness of snail seromucous and chitosan as anti TB drugs (ATD) in vitro.

METHODS: The research method is based on an experimental laboratory. MTB isolates in this research from sputum samples of patients suspected of TB in Surakarta Regional General Hospital. The stages of the study were performed MTB culture and identification, management sampling, and drug susceptibility testing

RESULTS: The research results showed chitosan 5\%; a combination of chitosan $9 \%$ and snail seromucous $50 \%$ (ratio 1:1) is a microbicide against MTB TB patient isolates. Snail seromucous was ineffective as a microbicide against MTB TB patients.

CONCLUSION: The effectiveness as a bactericide against MTB, chitosan, and its combination with snail seromucous has the potential to be an ATD alternative.
\end{abstract}

\section{Introduction}

Tuberculosis (TB) disease is an infection caused by Mycobacterium tuberculosis (MTB) and is transmitted through sputum droplets of sufferers or suspect TB in the air. TB treatment lasts quite a long time, namely, at least 6 months of treatment which results in the emergence of germ resistance so that TB treatment is not successful because patients drop out of treatment or undergo treatment irregularly resulting in Multi Drugs Resistance TB (MDR-TB).

Chitosan or $\beta$ - (1.4) -2 amino-2deoxy D-glucopyranose is a polysaccharide compound that can be obtained through the process of deacetylation of chitin compounds that are found in shrimp shells, crab shells. Chitosan synthesis uses samples of shrimp shells or crab shells, through the process of deacetylation with $60 \% \mathrm{NaOH}$ at $60-100^{\circ} \mathrm{C}$; deproteinization with $3.5 \%$ $\mathrm{NaOH}$, decalcification with $\mathrm{HCl} 2 \mathrm{~N}$, and color removal with acetone and $2 \% \mathrm{NaOCl}$ [1]. Chitosan has been widely used in the biomedical and pharmaceutical fields because it is a biocompatible, biodegradable, non-toxic, antimicrobial, and hydrating agent with positive effects on wound healing.

Seromucous of snail has anti-tumor bioactivity and is non-toxic to lymphocyte cells, and can even stimulate lymphocyte proliferation. Seromucous of snail as glycoprotein containing carbohydrates; $\alpha-1$ globulinoromucoid fraction; glycans, peptides, glycopeptides, and chondroitin sulfate. Chondroitin sulfate can function as an immunomodulator and immunosuppressant [2]. The content of Glycosaminoglycans, heparin, heparin sulfate, chondroitin sulfate, dermatan sulfate, and hyaluronic acid in snail seromucous can function as stabilizer cofactors and/or coreceptors for growth factors, cytokines, chemokines; enzyme activity regulator; molecular labeling in response to cellular damage in the process of wound healing, infection, tumorigenesis; targets for virulence factors of bacteria, viruses, parasites; as well as the immune system [3]. The antimicrobial activities of peptides isolated from the hemolymph of the molluscan garden snail Helix lucorum, which exhibited inhibition effects against Staphylococcus aureus, Staphylococcus epidermidis, and Escherichia coli. The achasin protein in the 
Achatina fulica Ferussac snail has important biological functions, including as a bacterial enzyme protein binding receptor [4]. Seromucous of snail $100 \%$ and $5 \%$ snail mucus cream preparation have an effective effect on accelerating the healing duration of second degree (A) burns. The combination of $100 \%$ snail mucus and $1.5 \%$ chitosan $=1: 2$ gave the optimum wound healing rate in the in vivo test. There is a synergistic effect of chitosan and seromucous of snail against $S$. aureus in vitro [5].

The diagnosis of TB can be performed based on clinical symptoms, chest X-ray, microscopic examination of smear sputum, smear culture on culture media as well as the sensitivity test of MTB isolates to anti TB drugs (ATD) and Drug Susceptibility Testing (DST). Until now there has been no research related to the effectiveness of snail chitosan and seromucous of snail as an alternative to ATD so that research related to this needs to be done.

The purpose of this research was to assess the effectiveness of chitosan and seromucous of snail as ATD in vitro. The essence of the research results is expected to be the potential of chitosan and seromucous of snail as an alternative to ATD.

\section{Materials and Methods}

This study and laboratory examinations were conducted and performed at Surakarta General Center Hospital from January to March 2020. All strains were isolated from culture-positive MTB cases. The TB diagnostic criteria were based on the Ministry of Health of the Republic of Indonesia (2014) and the corresponding WHO guidelines [6].

Seromucous of snail were collected from local snails ( $A$. fulica Ferussac) and chitosan powder was performed from Biotechsurindo factory, Cirebon, Indonesia. The dosage of ATD including were performed rifampicin (RIF) $(8000 \mathrm{mg} / \mathrm{L})$, isoniazid (INH) $(20 \mathrm{mg} / \mathrm{L})$, ethambutol (EB) $(200 \mathrm{mg} / \mathrm{L})$, and streptomycin (SM) (800 mg/L).

Clinical specimens including sputum were collected from patients with suspected TB of Surakarta General Center Hospital. The screening test was performed by microscopic examination of Ziehl Nelson staining and Molecular Quick Test - Genexpert instrument by following under relevance guidelines. The positive MTB isolates were subjected to cultivation with Lowenstein-Jensen medium (HiMedia, M162 product). All the MTB isolates were validated by both the growth test on p-nitrobenzoic acid (PNB) and MPT-64 antigen detection kit. Non-TB mycobacteria were excluded.

DST was performed using the MTB system. The colonies of MTB were swept from the agar plates and suspended in sterile saline containing $0.2 \%$ Tween and glass beads. After vortexing for at least $30 \mathrm{~s}$ to break up organisms clumps, the bacterial suspension was stayed for $15 \mathrm{~min}$ at room temperature to allow any remaining clumps to settle to the precipitations, and the supernatant was adjusted to then a suspension with a turbidity of $0.5-1.0$ Mc. Farland standard using a nephelometer. The dilution suspension was performed to $10^{-3}$ and $10^{-5}$. Stock solutions and working solutions were prepared. $100 \mu \mathrm{l}$ suspension of the subsequent suspension was inoculated to each tube of Lowenstein Jensen's media that contained freezedried seromucous, chitosan, and ATD including SIRE. The tube culture was incubated at $37^{\circ} \mathrm{C}$ for $28-42$ days. All steps were performed by trained and specialized persons in a biosafety cabinet by following under relevant guidelines [7].

The study results were analyzed using the statistical program of Statistical Package for the Social Sciences version 20.0 .

\section{Results}

Seromucous of snail collected from the amount of 10-50 snails, opened the end of the shell, and given the electric shock of 5-10 volts, for 30-60 s, and the liquid that comes out is collected in the flask container. Next, the liquid is centrifuged at $3500 \mathrm{rpm}$ for $10 \mathrm{~min}$ as hemolymph fluid or seromucous. Chitosan used in this research was dissolved in 5\% acetic acid solution [8].

Isolation and identification of MTB based on positive screening test results from sputum samples of suspect TB patients with the microscopic examination of the Ziehl Nelson method based on the scale International Union Against TB and Lung Disease scale, Genexpert test, culture on PNB media and MPT64 rapid test.

MTB resistance to Chitosan, Seromucous, Combination of Chitosan and Seromucous of Snail; ATD against MTB isolates as shown Table 1.

\section{Discussion}

Based on Table 1 shows that chitosan is $5 \%$; a mixture of chitosan $9 \%$ and seromucous of snail $50 \%$ (ratio 1:1) is a microbicide against MTB TB patient isolates. All MTB isolates of suspected TB patients were resistant to a single preparation of $100 \%$ seromucous of snail and $2 \%$ chitosan compared to ATD. Meanwhile, the most effective type of ATD as RIF is compared to other types of ATD, namely, SM, INH, and EB. 
Table 1: Percentage of MTB resistance to Chitosan, Seromucous, Combination of Chitosan and Seromucous of Snail; ATD against MTB isolates

\begin{tabular}{|c|c|c|c|c|c|c|}
\hline \multirow[t]{2}{*}{ Group } & \multirow[t]{2}{*}{ Dosage (\%) } & \multirow{2}{*}{$\begin{array}{l}\% \text { Resistance } \\
\text { of MTB }\end{array}$} & \multirow[t]{2}{*}{ Mean } & \multirow[t]{2}{*}{$p$-value } & \multicolumn{2}{|l|}{$\mathrm{Cl}$} \\
\hline & & & & & Upper & Lower \\
\hline \multirow[t]{7}{*}{ Chitosan } & 2 & 100 & 5.5 & 1.000 & 1.0 & 1.0 \\
\hline & 5 & 0 & 8.0 & 0.000 & 0.011 & 0.006 \\
\hline & 6 & 0 & 8.0 & 0.000 & 0.011 & 0.006 \\
\hline & 7 & 0 & 8.0 & 0.000 & 0.011 & 0.006 \\
\hline & 8 & 0 & 8.0 & 0.000 & 0.011 & 0.006 \\
\hline & 9 & 0 & 8.0 & 0.000 & 0.011 & 0.006 \\
\hline & 10 & 0 & 8.0 & 0.000 & 0.011 & 0.006 \\
\hline \multirow[t]{7}{*}{ Seromucous of Snail } & 25 & 100 & 5.5 & 1.000 & 1.000 & 1.000 \\
\hline & 30 & 100 & 5.5 & 1.000 & 1.000 & 1.000 \\
\hline & 35 & 100 & 5.5 & 1.000 & 1.000 & 1.000 \\
\hline & 40 & 100 & 5.5 & 1.000 & 1.000 & 1.000 \\
\hline & 45 & 100 & 5.5 & 1.000 & 1.000 & 1.000 \\
\hline & 50 & 100 & 5.5 & 1.000 & 1.000 & 1.000 \\
\hline & 100 & 100 & 5.5 & 1.000 & 1.000 & 1.000 \\
\hline Ratio & C $2: S S 25$ & 100 & 5.5 & 1.000 & 1.000 & 1.000 \\
\hline Chitosan:Seromucous & C 5 :SS 30 & 100 & 5.5 & 1.000 & 1.000 & 1.000 \\
\hline \multirow{5}{*}{ of snail $=1: 1$} & C $6: S S 35$ & 100 & 5.5 & 1.000 & 1.000 & 1.000 \\
\hline & C $7:$ SS 40 & 100 & 5.5 & 1.000 & 1.000 & 1.000 \\
\hline & C $8: S S 45$ & 100 & 5.5 & 1.000 & 1.000 & 1.000 \\
\hline & C 9:SS 50 & 0 & 8.0 & 0.000 & 0.011 & 0.006 \\
\hline & C $10:$ SS 100 & 0 & 8.0 & 0.000 & 0.011 & 0.006 \\
\hline \multirow[t]{4}{*}{ ATD } & $S(S M)$ & 60 & 6.5 & 0.134 & 0.462 & 0.436 \\
\hline & I (INH) & 20 & 7.5 & 0.014 & 0.510 & 0.400 \\
\hline & R (RIF) & 0 & 8.0 & 0.000 & 0.011 & 0.006 \\
\hline & $E(E B)$ & 100 & 5.5 & 1.000 & 1.000 & 1.000 \\
\hline Negative control & & 100 & 5.5 & 1.000 & 1.000 & 1.000 \\
\hline
\end{tabular}

The ineffectiveness of the snail seromucous as ATD in vitro is due to the physicochemical properties of the preparation, namely, the solubility or polarity of the bioactive compound which is not able to penetrate the permeability of MTB cells in order that the dosage of the bioactive compound of snail seromucous is used, it not optimal as a bactericide. Furthermore, the difference within the variation in antibacterial activity is influenced by differences in the resistance level of the inoculum strain associated with the resistance gene expression results.

Chitosan is a $\beta$ - (1.4) -2 amino-2deoxy D-glucopyranose compound, as a product of chitin deacetylation. Chitosan has been widely utilized in the biomedical and pharmaceutical fields because its biodegradable, non-toxic, non-immunogenic, and biocompatible with animal body tissues. The effectiveness of chitosan as an antimicrobial is related to the role of the Chito-Oligosaccharide (COS) compound, a group of complex compounds glycan-binding protein that has a 1,4-b-glucosamine, which is a derivative of chitosan deacetylation of chitin. The effect of COS as the antimicrobial activity is highly dependent on the degree of deacetylation and polymerization of the types of bacteria and fungi. COS as a potential material as "alternative antibiotics" has a value of more effective without causing residue. The uniqueness of chitosan is that it's polycationic in order that it can suppress the growth rate of diarrhealgenic E. coli in vitro [9].

The seromucous of snail contains various types of achasin proteins that have important biological functions, including receptors for binding bacterial enzymes. The effectiveness of the bactericide and or bacteriostatic snail mucus against the isolates of Staphylococcus sp, Streptococcus sp, and Pseudomonas sp showed varied results [10]. The
$100 \%$ concentration of snail seromucous is capable of being bactericidal against $S$. aureus, Candida albicans, and Pseudomonas aeruginosa [11]. The results of the Minimal Inhibition Concentration test of meat protein extract from seven, different types of snails showed varied results because they were influenced by the ecological conditions of the snails [12]. Seromucous of snail is antibacterial against Streptococcus mutans; $E$. coli and inhibits the growth of Methicillin-Resistant S. aureus [13]. The $100 \%$ snail mucus concentration is capable of being bacteriostatic against the growth of S. aureus and Salmonella typhosa [14]. Some of the protein lectins are known to be contained in snails, namely, selectin, galectin, C-type lectin, and fibrinogenrelated protein which are secreted by snails that plays a role within the pathogen agglutination process [15].

Based on these results, chitosan and its mixture with seromucous snail are potential candidates for ATD. The content of bioactive compounds in chitosan and seromucous snail can stimulate the function of cellular immunity, namely, lymphocyte proliferation and the production of reactive oxygen intermediated macrophages. The results of the characterization of the snail seromucous protein profile using the SDS-PAGE method showed that have been 3 protein subunits, namely the range of $55-72 \mathrm{kDa}$ because the achasin sulfate group that acted as an antimicrobial and 1 specific protein subunit $43 \mathrm{kDa}$ as adhesive protein. The $100 \%$ seromucous of snail and $5 \%$ snail slime cream showed optimum effectiveness against lymphocyte proliferation in vitro [16]. The research being carried out is freeze-drying seromucous of snail preparation.

The factor causing the ineffectiveness of a microbicidal agent is additionally influenced by the physiological characteristics of MTB isolates which have specific characteristics compared to the physiology of other bacterial cells, namely the presence of mycolic acid in the cell walls which acts as a virulence factor for MTB cells. The effectiveness of a bactericidal or bacteriostatic drug against MTB isolates is often influenced by the physiology of bacterial cells, namely genetic factors associated with the extent of resistance or virulence of cells to an agent or the mutation process caused by mutagenic agents, physically and chemically, from environmental factors. In MTB cells have mycolic acid (trehalose dimycolate) which plays an important role in pathogenic interactions with the host. Mycolic acid has a similar function with lipopolysaccharide in Gram-negative bacterial cells. Mycolic acid affects the function of macrophages, namely inhibiting the fusion of macrophages in host cells against pathogens. The presence of mycolic acid in MTB plays a crucial role within the level of germ resistance to host immune cells and drugs. Each type of ATD contains a different mechanism of action so that it affects the effectiveness of bactericide as ATD. The mechanism of action of SM interferes with the translation process by binding to $16 \mathrm{~s}$ rRNA in protein synthesis. INH inhibits the synthesis of 
mycolic acid so INH is that the best ATD for the treatment and prevention of TB. INH resistant strains often appear with a frequency of around $90 \%$ and therefore the resistance is caused by mutations in one in every of the catalase-peroxidase (KatG), inhA, or ahpC genes. $\mathrm{INH}$ in cells will turn active in an oxidized form because of activation of the enzyme KatG which is encoded by the KatG gene. The KatG gene encodes the enzyme KatG which activates INH as a prodrug in order that mutations within the gene cause the enzyme to become inactive. Other mechanisms of resistance to INH and ethionamide $(\mathrm{ETH})$ are changes in the expression of drug activators, redox changes, drug inactivation, and efflux pump activation [17]. Mode of action RIF a bactericide by inhibiting nucleic acid synthesis by binding to the $\beta$ RNA polymerase subunit within the RNA transcription process. The resistance of MTB to RIF reaches $95 \%$ and occurs due to the mutation of the rpo $B$ gene that encodes the $\beta$ RNA polymerase subunit as a very important component within the transcription process. The transcription process is inhibited because RIF is specifically bound to the $\beta$ RNA polymerase subunit. EB could be a bactericide by interfering with carbohydrate metabolism and cell wall biosynthesis. While pyrazinamide (PZA) as an analog of nicotinamide structure is bactericidal because pyrazinoic acid as a result of the activity of the PZA enzyme formed under acidic conditions. PZA resistance occurs because of mutations within the pncA gene that cause loss of PZA activity (PZAase) so that the mechanism of action of PZA becomes inactive when entering the cell of MTB resistance to $E B$ because of mutations in the embB gene that encodes arabinosil transferase so that biosynthesis or wall polymerization is inhibited arabinan cells as arabinogalactans components and therefore the occurrence of the accumulation of decaprenol phosphoarabinose lipid carriers [18].

The level of resistance of MTB isolates to ATD can occur due to the physiological properties of cells or MTB resistant strains that are different in each region due to the occurrence of mutations that are not interdependent (independent mutation) in additional than one ATD coding gene and or gene coding enzyme for precursor activation enzymes ATD. Mutations occurred within the process of protein synthesis are transcription and or translational processes that have a control on the expression of those genes, resulting in changes within the structure of the target protein or changes in enzymatic activity needed to activate ATD compounds to function as bactericides.

The immune response plays an important role in MTB infection. Most of the people are infected with Mycobacteria, 90\% don't develop TB. Macrophages in host cells play a vital role within the immune system, namely phagocytosis of cellular antigens. Bacteria within the lung are phagocytes by alveolar macrophages. MTB in macrophages can change the environment by inhibiting the acidification process in phagosome maturation which ends within the phagosome maturation process being stopped. This ends up in phagosomes not having the ability to fusion with lysosomes in order that MTB cannot be destroyed and continues to replicate in macrophages [19]. Treatment of TB with ATD to date has been given the correct ATD; however, there are many strains of MTB resistant to two or more ATD called MDR-MTB strains. The prevalence of MDR-TB and extensively drug-resistant TB is higher in the case of recurrent TB treatment compared to the initial TB case and also the variation within the level of TB germ resistance to ATD is influenced by age, sex, and region [20]. There are side effects in MDR-TB therapy and also the correlation between cure rates and resistance to ATD so that a psychological social management approach is needed in MDR-TB patients and the presence of a bacterial profile related to resistance against antibiotics and TB treatment. This is often to the patient's ignorance of the disease, poor patient compliance, administration of monotherapy or effective drug regimens, inadequate doses, poor instructions, low medication regularity, poor patient motivation, irregular drug supply, poor bioavailability, and poor quality of the drug contributes to the occurrence of secondary drug resistance. Resistance encourages the employment of other more toxic alternative medicines, namely, ETH, aminosalicylic acid, cycloserine, capreomycin, ciprofloxacin, or ofloxacin. The emergence of MTB strains that are resistant to two or more ATD causes the failure rate of TB therapy to be high.

\section{Conclusion}

Chitosan 5\%; a combination of chitosan $9 \%$ and snail seromucous $50 \%$ (ratio 1:1) could be a microbicide against MTB TB patient isolates. Seromucous of snail was ineffective as a microbicide against MTB TB patients. Given its effectiveness as a bactericide against MTB, chitosan and its mixture with snail seromucous have the potential to be an ATD alternative. Further research is required regarding the optimum dosage formulation and also the synergistic effect of seromucous and chitosan preparations with other ATD.

\section{Acknowledgments}

The researcher is grateful to the Center for Research and Community Service of Universitas Kusuma Husada Surakarta; Chief of Laboratory Microbiology of Surakarta General Center Hospital. 
This research was funded by the Kusuma Husada University Institutional Competitive Research Grant.

\section{References}

1. Ibrahim K, El-Eswed B, Abu-Sbeih K, Arafat T, Omari MA, Darras $F$, et al. Preparation of chito-oligomers by hydrolysis of chitosan in the presence of zeolite as adsorbent. Mar Drugs. 2016;14(8):43. https://doi.org/10.3390/md14080043 PMid:27455287

2. Zhuang J, Coates $\mathrm{C}$, Zhu H, Zhu P, Wu Z, Xie L, et al. Identification of candidate antimicrobial peptides derived from abalone hemocyanin. Immunol Dev Comp. 2015;49(1):96-102. https://doi.org/10.1016/j.dci.2014.11.008

PMid:25445903

3. Dang V, Benkendorff K, Green T, Speck P. Marine snails and slugs: A great place to look for antiviral drugs. J Virol. 2015;89(16):8114-8. https://doi.org/10.1128/jvi.00287-15 PMid:26063420

4. Dolashka P, Dolashki A, Voelter W, Beeumen JV, Stevanovic S. Antimicrobial activity of peptides the hemolymph of Helix lucorum snails. Int J Curr Microbiol App Sci. 2015;4(4):1061-71. https://doi.org/10.2174/1389201016666150907113435

5. Harti A, Sulisetyawati S, Murharyati A, Oktariani M, Wijayanti I. The effectiveness of snail slime and chitosan in wound healing. Int J Pharm Med Biol Sci. 2016;5(1):76-80.

6. National Guidelines for Controlling Tuberculosis. Ministry of Health Republic of Indonesia. Jakarta: National Guidelines for Controlling Tuberculosis; 2014.

7. Ministry of Health Republic of Indonesia. Health Ministry of the Republic of Indonesia. Tuberculosis. Indonesia: Ministry of Health Republic of Indonesia; 2018. https://doi.org/10.18311/ jeoh/2020/26134

8. Octaviana U, Maryati A, Fatimah S, Harti A. Chitosan Biomembrane as Sanitary Pads. Final Report of the Creativity Students Program; 2015.

9. Harti A, Kusumawati H, Siswiyanti S, Setyaningtyas A. In vitro synergistics effects of snail slime and chitosan against Staphylococcus aureus. Int J Pharm Med Biol Sci. 2016;5(2):137-41.

10. Etim L, Aleruchi C, Obande G. Antibacterial properties of snail mucus on bacteria isolated from patients with wound infection. $\mathrm{Br}$ Microbiol Res J. 2016;11(2):1-9. https://doi.org/10.9734/ bmrj/2016/21731

11. Harti A, Puspawati N, Putriningrum R. Antimicrobial bioactive compounds of snail seromucous as biological response modifier immunostimulator. Indones Microbiol 2019;13(3):56-63. https:// doi.org/10.5454/mi.13.2.3

12. Ulagesan $\mathrm{S}, \mathrm{Kim} \mathrm{H}$. Antibacterial and antifungal activities of proteins extracted from seven different snails. Appl Sci. 2018;8(8):1362. https://doi.org/10.3390/app8081362

13. Anggraini D, Darmawati S, Endang T. Protein Profile and Anti-microbial Power of Snail Slime (Achantina fulica) against Methicillin Resistant Staphylococcus aureus (MRSA). Student National Seminar 1: of Universitas Muhammadiyah Semarang; 2018. p. 73-7.

14. Nantarat N, Tragoolpua Y, Gunama P. Antibacterial activity of the mucus extract from the giant African Snail (Lissachatina fulica) and golden apple snail (Pomacea canaliculata) Against Pathogenic Bacteria Causing Skin Diseases. Trop Nat Hist Chulalongkorn Univ. 2019;19(2):103-12. https://doi. org/10.36468/pharmaceutical-sciences.673

15. Dolashka P, Dolashki A, Beeumen JV, Floetenmeyer $M$, Velkova L, Stevanovic S, et al. Antimicrobial activity of molluscan hemocyanins from helix and rapana snails. Curr Pharm Biotechnol. 2016;17(3):263-70. https://doi.org/10.2174/ 1389201016666150907113435 PMid:26343131

16. Harti A, Murharyati A, Sulisetyawati S, Oktariani M. The effectiveness of snail mucus (Achantina fulica) and chitosan towards lymphocyte proliferation in vitro. Asian J Pharm Clin Res. 2018;11(15):85-8. https://doi.org/10.22159/ajpcr.2018. v11s3.30041

17. Vilchèze $\mathrm{C}$, Jacobs $\mathrm{W}$. Resistance to isoniazid and ethionamide in Mycobacterium tuberculosis: Genes, mutations, and causalities. Microbiol Spectr. 2014;2(4):MGM2-0014-2013. https://doi.org/10.1128/microbiolspec.mgm2-0014-2013 PMid:26104204

18. Kiepiela P, Bishop K, Smith A, Roux L, York D. Genomic mutations in the katG, inhA and aphC genes are useful for the prediction of isoniazid resistance in Mycobacterium tuberculosis isolates from Kwazulu Natal, South Africa. Tuber Lung Dis. 2000;80(1):47-56. https://doi.org/10.1054/tuld.1999.0231 PMid: 10897383

19. Burkovski A. Cell envelope of corynebacteria: Structure and influence on pathogenicity. ISRN Microbiol. 2013;2013:935736. https://doi.org/10.1155/2013/935736 PMid:23724339

20. Wu X, Yang J, Tan G, Liu H, Liu Y, Guo Y, et al. Drug resistance characteristics of Mycobacterium tuberculosis isolates from patients with tuberculosis to 12 antituberculous drugs in China. Front Cell Infect Microbiol. 2019;9:345. https://doi.org/10.3389/ fcimb.2019.00345

PMid:31828045 